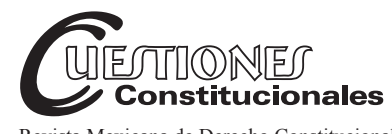

Revista Mexicana de Derecho Constitucional Núm. 42, enero-junio 2020

\title{
El parámetro de regularidad constitucional y la ley suprema de la Unión
}

\section{The Parameter of Constitutional Regularity and the Supreme Law of the Land}

\begin{abstract}
RESUMEN: Este trabajo tiene por objeto estudiar el proceso de resignificación del concepto "ley suprema de la Unión" contenido en el artículo 133 constitucional, a partir de la identificación y desarrollo del parámetro de regularidad constitucional, por parte de la Suprema Corte de Justicia de la Nación. Para ello, procederemos en primer lugar a estudiar el concepto de la ley suprema de la Unión prestando especial atención a las variaciones observables en su contenido con relación a la ubicación del derecho de fuente internacional. Luego, analizaremos la conformación del parámetro de regularidad constitucional como bloque de derechos y los problemas para la solución de diferencias y antinomias en su interior. En la tercera sección procederemos a determinar las transformaciones generadas en el contenido de la ley suprema de la Unión a partir de la incorporación del parámetro de regularidad constitucional.
\end{abstract}

Palabras clave: ley suprema de la Unión; parámetro de regularidad constitucional; bloque de constitucionalidad; bloque de derechos; control constitucional.

\section{Juan Manuel ACUÑA*}

ABSTRACT: The purpose of this paper is to study the re signification process of the supreme law of the Union contained in article 133 of the Constitution, based on the identification and development of the constitutional regularity parameter by the Supreme Court of Justice of the Nation. In order to do so, we will first proceed to study the concept of the supreme law of the Union giving special attention to the observable variations in its content in relation to the location of the international source right. Then, we will analyze the conformation of the parameter of constitutional regularity as a block of rights and the problems for the solution of differences and antinomies in its interior. In the third section we will proceed to determine the transformations generated in the content of the supreme law of the union from the incorporation of the parameter of constitutional regularity.

Keywords: Supreme Law of the Land; Parameter of Constitutional Regularity; Constitutional Control.

* Profesor e investigador de la Facultad de Derecho de la Universidad Panamericana, México. Director de la Maestría en Derecho Procesal Constitucional. Sistema Nacional de Investigadores, nivel I. ORCID: 0000-0003-4330-6176. Correo: jmacuna@up.edu.mx. 
SUMARIO: I. Explicación preliminar. II. Preámbulo. La supremacía constitucional en tiempos del constitucionalismo cosmopolita. III. La ley suprema de la Unión y los tratados internacionales. IV. El parámetro de regularidad constitucional. V. El parámetro de regularidad constitucional en la ley suprema de la

Unión. VI. Conclusiones. VII. Bibliohemerografía.

\section{EXPLICACIÓN PRELIMINAR}

Este trabajo tiene por objeto explicar la conformación del parámetro de regularidad constitucional a partir de la reforma constitucional de derechos humanos del 10 de junio de 2011 y del trabajo interpretativo de la Suprema Corte de Justicia de la Nación, así como la resignificación que produjo en el concepto "ley suprema de la Unión". En la primera sección analizaremos el concepto y contenido de la "ley suprema de la Unión" para dar cuenta de sus variaciones y problemas internos más significativos. Nos enfocaremos en las relaciones que en su interior mantuvieron sus componentes de fuente interna con el derecho de fuente internacional, hasta antes de la reforma de derechos humanos. En segundo término, analizaremos el proceso de configuración del parámetro de regularidad constitucional que llevó a cabo la Suprema Corte de Justicia de la Nación. Nos detendremos en el estudio de la generación de contradicciones al interior del parámetro y en el análisis de opciones para procurar solucionarlas. Por último, explicaremos la resignificación del concepto "ley suprema de la Unión" a partir de su ensamble con el parámetro de regularidad constitucional como bloque de derechos.

\section{PreÁmbulo. LA SUPREMACíA CONSTITUCIONAL EN TIEMPOS DEL CONSTITUCIONALISMO COSMOPOLITA}

El artículo 133 - junto a otras disposiciones constitucionales - recepta en nuestro sistema el principio de supremacía constitucional, nota entitativa de las Constituciones. ${ }^{1}$ La Constitución por ser suprema, es la norma a la

\footnotetext{
1 Carpizo, Jorge, Estudios constitucionales, México, UNAM, Instituto de Investigaciones Jurídicas, 1996, pp. 1 y 2. 
que está sujeta la creación del resto de las normas, por ciertos órganos superiores estatales. ${ }^{2}$ Pero la Constitución es suprema también en un sentido normativo y, como tal, es inmune a las leyes ordinarias y a la vez, determinante de la validez de éstas. ${ }^{3}$ Este principio fue claramente expresado por Alexander Hamilton en El Federalista LXXVIII $^{4}$ y luego por el juez Marshall en la multicitada sentencia Marbury vs. Madison ${ }^{5}$ y sobre la base de estas ideas continuamos entendiendo a la supremacía de las Constituciones.

La Constitución ocupa entonces la cúspide del ordenamiento jurídico y del complejo concepto "ley suprema de la Unión", en cuyo seno en principio fue entendida como supra ordenada a los tratados y a las leyes que emanen del Congreso de la Unión. Sobre la conformación del complejo normativo denominado "ley suprema de la Unión" volveremos más adelante, pero debemos anticipar que debido al desarrollo del derecho internacional de los derechos humanos y de los órganos de protección regionales e internacionales, se han recortado ámbitos decisorios en cada sistema jurídico nacional. Los espacios resolutivos, aun los constitucionales, han visto disminuida su libertad configurativa y en este sentido y en la actuali-

2 De Otto, Ignacio, Derecho constitucional, sistema de fuentes, Barcelona, Ariel Derecho, 1998, p. 15.

3 García de Enterría, Eduardo, La Constitución como norma y el Tribunal Constitucional, Madrid, 3a. ed., Civitas, 1983, pp. 30 y 31.

4 "No hay proposición que se apoye sobre principios más claros que la que afirma que todo acto de una autoridad delegada, contrario a los términos del mandato con arreglo al cual se ejerce, es nulo. Por lo tanto, ningún acto legislativo contrario a la Constitución puede ser válido. Negar esto equivaldría a afirmar que el mandatario es superior al mandante, que el servidor es más que su amo, que los representantes del pueblo son superiores al pueblo mismo...", en Hamilton, A., Madison, J. y Jay, J., El Federalista, trad. de Gustavo Velasco, México, Fondo de Cultura Económica, 2000. p. 332.

5 "Está fuera de toda duda que o la Constitución se impone a cualquier ley que la contradiga o, por el contrario, el Legislativo puede modificar la Constitución a través de una ley cualquiera. Entre estas dos opciones no hay término medio. O la Constitución es un derecho superior, principal e inmodificable a través de mecanismos ordinarios, o, por el contrario, se sitúa al mismo nivel que las leyes ordinarias, y como toda ley, es modificable cuando así lo disponga la voluntad del Legislativo. Si la primera parte de la alternativa fuera cierta, entonces una ley contraria a la Constitución no es derecho. Si la cierta fuese la última parte, entonces, las Constituciones escritas no serían más que intentos absurdos del pueblo de limitar un poder que por naturaleza escaparía a todo límite", "Sentencia Marbury vs. Madison (1803)", en Beltrán de Felipe, Miguel y González García, Julio V. (coords.), Las sentencias básicas del Tribunal Supremo de los Estados Unidos de América, Madrid, Boletín oficial del Estado, Centro de Estudios Políticos y Constitucionales, 2006, pp. 93 y ss. 
dad, las Constituciones aún son supremas, aunque en un sentido diferente a aquel que tradicionalmente se les ha atribuido. La libertad configurativa de las Constituciones debe garantizar los mínimos convencionales en materia de derechos humanos, pero esos mínimos no sólo restringen la libertad configurativa en un momento estático, como al ratificar un tratado internacional cuando se adquiere un compromiso respecto a lo establecido en el texto del tratado, sino también - y en ocasiones no se suele reparar en esto-, se adquiere un compromiso en cierto modo, "a ciegas", para aceptar aquello que los órganos del tratado establecerán, como intérpretes auténticos del mismo a la luz claro de un trabajo interpretativo razonable. En otros términos, cuando los Estados asumen compromisos internacionales, en ocasiones no están del todo claras las especificidades de tales compromisos, lo que, con el tiempo, tenderá a provocar resistencias.

La relación entre la Constitución y el derecho internacional se tiende a entorpecer cuando anclamos el concepto de supremacía en la nota de soberanía, sin reparar que la Constitución - y los valores y notas que le atribuimos- es antes que un producto estatal, un producto del constitucionalismo y la supremacía de las Constituciones nacionales se resiente ante el auge del constitucionalismo cada vez más inscrito en clave cosmopolita e internacional. Ferrajoli ha explicado muy bien este asunto: el constitucionalismo — nos cuenta - es un paradigma que nace ligado a tres ideas: la defensa de los derechos de libertad, la limitación al poder político y todo ello, dentro de los confines del Estado nación. La historia del constitucionalismo es la de la expansión de estas variables: de la protección de los derechos civiles a la protección del constitucionalismo social, de limitar sólo al Estado a limitar además al mercado y, por último, la generación de un constitucionalismo mundial que complementa a los constitucionalismos nacionales. ${ }^{6}$ En este proceso, la constitución como producto nacional se resiste frente al constitucionalismo como movimiento supranacional y cosmopolita. ${ }^{7}$ El constitucionalismo comienza a deslindarse del Estado dando lugar a aquello que García Jaramillo ha denominado "constitucionalismo genérico", fruto de un proceso de naturaleza globalizadora, que en nuestro ámbito se puede denominar interamericanización del derecho. ${ }^{8}$

\footnotetext{
6 Ferrajoli, Luigi, Democracia y garantismo, Madrid, Trotta, 2008, pp. 35 y 36.

7 Para un estudio acerca de las relaciones entre Constitución y soberanía y el proceso de conformación de la visión estatalista de los derechos, véase, Fioravantim, Maurizio, Los derechos fundamentales, Apuntes de historia de las Constituciones, Madrid, 1996.

8 García Jaramillo, Leonardo, "Desafíos de la interamericanización del derecho: la 
Con estas ideas en mente, se puede asumir que los problemas generados en el proceso de construcción del parámetro de regularidad constitucional y las dificultades para su ensamble adecuado en el complejo normativo conformado por la ley suprema de la Unión, se deben a una inadecuada comprensión de las nuevas relaciones entre la Constitución y el derecho internacional de los derechos humanos en el escenario del constitucionalismo cosmopolita.

\section{LA LEY SUPREMA DE LA UNIÓN Y LOS TRATADOS INTERNACIONALES}

La ley suprema de la Unión es uno de los conceptos centrales contenidos en el artículo 133 constitucional, junto con el principio de supremacía de la Constitución y el reconocimiento de la facultad de ejercicio de control constitucional a los jueces locales. Además, debemos incluir el tratamiento de temas más específicos como la relación entre el orden federal y los órdenes locales y - de relevancia para nuestro tema- los componentes de la ley suprema de la Unión y la relación que guardan entre sí. ${ }^{9}$

A lo largo de los años, estos temas han generado desacuerdos y los conceptos mencionados han tenido diversos significados connotativos o bien variaciones significativas en cuanto a las formas de vinculación entre sí. Un claro ejemplo lo encontramos en las diversas connotaciones acerca de uno de los componentes de la ley suprema de la unión, "las leyes del Congreso de la Unión que emanen de ella", es decir, de la Constitución. Durante años, la doctrina discutió acerca de la naturaleza y concepto de dichas leyes. ${ }^{10}$ Con el tiempo, y amén de las divergencias doctrinales, el

contribución del ius constitutionale commune", en von Bogdandy, Armin; Morales Antoniazzi, Mariela y Ferrer Mac-Gregor, Eduardo (coords.), Ius constitutionale commune en América Latina, México, Instituto de Estudios Constitucionales de Querétaro y Max Planck Institute, 2017, pp. 577-605.

9 Carpizo, Jorge, op. cit., p. 2.

10 Para un estudio en clave histórica de las diferentes opiniones acerca del concepto de las leyes a las que alude el artículo 133, véase, entre otros: Fraga, Gabino, Derecho administrativo, 37 ed., México, Porrúa, 2015, pp. 39 y ss. García Máynez, Eduardo, Introducción al estudio del derecho, 65 ed., México, Porrúa, 2015, pp. 85 y ss.; Cueva, Mario de la, Teoría de la Constitución, México, Porrúa, 2008, pp. 114 y ss.; Carpizo, Jorge, Estudios constitucionales, México, UNAM, Instituto de Investigaciones Jurídicas, 1996. Fix-Zamudio, Héctor y Valencia Carmona, Salvador, Derecho constitucional mexicano y comparado, 9a. ed., México, UNAM-Porrúa, 2017, pp. 72 y 73, entre otros. 
concepto parece haberse estabilizado a partir de la identificación realizada por el Tribunal Pleno de la Suprema Corte de Justicia de la Nación al resolver el amparo en revisión 120/2002 y establecer que las leyes a las que refiere el artículo 133 constitucional no son las leyes federales ordinarias, ni las constitucionales, sino las leyes generales por las que debemos entender aquellas que son dictadas para incidir en todos los órdenes jurídicos parciales, que tienen su origen en cláusulas constitucionales y que tienen por objeto distribuir competencias en materias concurrentes. ${ }^{11}$

Sin embargo, las variaciones más relevantes para nuestro tema son aquellas que se generaron con relación al lugar de los tratados internacionales con respecto a los demás componentes de la ley suprema de la Unión y si un tipo especial de tratados o bien, un cierto contenido de los tratados, los derechos humanos, debería guardar una relación diferente con el resto del ordenamiento jurídico. Tradicionalmente, la incorporación de los tratados internacionales de la materia que sea y su relación con las otras partes integrantes de la ley suprema de la Unión fue entendida en términos de jerarquía. Un rápido repaso a las principales decisiones de la Suprema Corte al respecto corroborará esta afirmación.

Con ocasión de la resolución del amparo en revisión 2069/92, el Pleno de la Suprema Corte de Justicia de la Nación determinó que las leyes federales y los tratados internacionales tenían la misma jerarquía. La Corte no

11 Tesis: P. VII/2007, Semanario Judicial de la Federación y su Gaceta, t. XXV, abril de 2007, p. 5. "LEYES GENERALES. INTERPRETACIÓN DEL ARTÍCULO 133 CONSTITUCIONAL. La lectura del precepto citado permite advertir la intención del Constituyente al establecer un conjunto de disposiciones de observancia general que, en la medida en que se encuentren apegadas a lo dispuesto por la Constitución Política de los Estados Unidos Mexicanos, constituyan la «Ley Suprema de la Unión»". En este sentido, debe entenderse que las leyes del Congreso de la Unión, a las que se refiere el artículo constitucional, no corresponden a las leyes federales, esto es, a aquellas que regulan las atribuciones conferidas a determinados órganos con el objeto de trascender únicamente al ámbito federal, sino que se trata de leyes generales que son aquellas que pueden incidir válidamente todos los órdenes jurídicos parciales que integran el Estado mexicano. Es decir, las leyes generales corresponden a aquellos respecto a las cuales el Constituyente o el Poder Revisor de la Constitución ha renunciado expresamente a su potestad distribuidora de atribuciones entre las entidades políticas que integran el Estado mexicano, lo cual se traduce en una excepción al principio establecido por el artículo 124 constitucional. Además, estas leyes no son emitidas motu propio por el Congreso de la Unión, sino que tienen su origen en cláusulas constitucionales que obligan a éste a dictarlas, de tal manera que una vez promulgadas y publicadas, deberán ser aplicadas por las autoridades federales, locales, del distrito federal y municipales". 
hizo eco de las distinciones efectuadas por la doctrina y se refirió a leyes federales sin más. Por ello es posible intuir también que en esta decisión la Corte participó de la idea de preminencia del orden federal sobre el local. En lo referente a las relaciones al interior de la ley suprema de la Unión, ubicó a las leyes federales y a los tratados internacionales en el mismo nivel jerárquico. ${ }^{12}$

Años después, y ya en la Novena Época, al resolver el amparo en revisión 1457/98, el Tribunal Pleno modificó sustancialmente el criterio anterior al determinar los criterios de supra legalidad e infra constitucionalidad, según los cuales los tratados internacionales se ubican por encima de las leyes federales y por debajo de la Constitución federal. ${ }^{13} \mathrm{La}$

12 Tesis: P. C/92, Gaceta del Semanario Judicial de la Federación, Octava Época, núm. 60, diciembre de 1992, p. 27. "LEYES FEDERALES Y TRATADOS INTERNACIONALES. TIENEN LA MiSMa JERARQuía NORMATIVA. De conformidad con el artículo 133 de la Constitución, tanto las leyes que emanen de ella como los tratados internacionales, celebrados por el Ejecutivo Federal, aprobados por el Senado de la República y que estén de acuerdo con la misma, ocupan, ambos, el rango inmediatamente inferior a la Constitución en la jerarquía de normas en el orden jurídico mexicano. Ahora bien, teniendo la misma jerarquía, el tratado internacional no puede ser criterio para determinar la constitucionalidad de una ley ni viceversa. Por ello, la Ley de las Cámaras de Comercio y de la Industria, no puede ser considerada inconstitucional por contrariar lo dispuesto en un tratado internacional".

13 Tesis P. LXXVII/99, Semanario Judicial de la Federación y su Gaceta, Novena Época, t. X, noviembre de 1999, p. 46. "TRATADOS INTERNACIONALES. SE UBICAN JERÁRQUICAMENTE POR ENCIMA DE LAS LEYES FEDERALES Y EN UN SEGUNDO PLANO RESPECTO DE LA CONSTITUCiÓn FEDERAL". Persistentemente en la doctrina se ha formulado la interrogante respecto a la jerarquía de las normas en nuestro derecho. Existe unanimidad respecto de que la Constitución federal es la norma fundamental y que aunque en principio la expresión «...será la ley suprema de la Unión...» parece indicar que no sólo la carta magna es la suprema, la objeción es superada por el hecho de que las leyes deben emanar de la Constitución y ser aprobadas por un órgano constituido, como lo es el Congreso de la Unión y de que los tratados deben estar de acuerdo con la ley fundamental, lo que claramente indica que sólo la Constitución es la ley suprema. El problema respecto a la jerarquía de las demás normas del sistema ha encontrado en la jurisprudencia y en la doctrina distintas soluciones, entre las que destacan: supremacía del derecho federal frente al local y misma jerarquía de los dos, en sus variantes lisa y llana y con la existencia de leyes constitucionales, y la de que será ley suprema la que sea calificada de constitucional. No obstante, esta Suprema Corte de Justicia, considera que los tratados internacionales se encuentran en un segundo plano inmediatamente debajo de la ley fundamental y por encima del derecho federal y local. Esta interpretación del artículo 133 constitucional, deriva de que estos compromisos internacionales son asumidos por el Estado mexicano en su conjunto y comprometen a todas las autoridades frente a la comunidad internacional; por ello se explica que el Constituyente haya facultado al presidente de la República 
determinación más importante consistió en la modificación de su anterior criterio sobre la ubicación de los tratados. La segunda determinación fue el reconocimiento expreso de las leyes constitucionales, distinción a la que no dio efecto alguno. Por último, el juicio más confuso allí vertido fue el referido a que la expresión "ley suprema de la Unión" sólo incluiría a la Constitución federal. La literalidad del artículo 133 es clara en el sentido de indicar que ese concepto tiene una integración compleja cuyo contenido no se circunscribe a la Constitución —amén de la relación jerárquica interna entre sus componentes-.

La siguiente determinación importante fue tomada por el Tribunal Pleno de la Suprema Corte en el ya mencionado amparo en revisión 120/2002. Sobre el tema específico de la relación de los tratados internacionales con el resto de los componentes del concepto de ley suprema de la Unión, la Corte sostuvo que los tratados internacionales — sin distinción-, poseían rango supra legal e infra constitucional. En este sentido, ratificó su criterio anterior y la adaptó al concepto de leyes generales identificado en esta misma resolución. ${ }^{14}$

a suscribir los tratados internacionales en su calidad de jefe de Estado, y, de la misma manera, el Senado interviene como representante de la voluntad de las entidades federativas, y por medio de su ratificación, obliga a sus autoridades. Otro aspecto importante para considerar esta jerarquía de los tratados, es la relativa a que en esta materia no existe limitación competencial entre la Federación y las entidades federativas, esto es, no se toma en cuenta la competencia federal o local del contenido del tratado, sino que por mandato expreso del propio artículo 133, el presidente de la República y el Senado pueden obligar al Estado mexicano en cualquier materia, independientemente de que para otros efectos, ésta sea competencia de las entidades federativas. Como consecuencia de lo anterior, la interpretación del artículo 133 constitucional lleva a considerar en un tercer lugar, al derecho federal y al local, en una misma jerarquía en virtud de lo dispuesto por el artículo 124 de la ley fundamental, el cual ordena que las facultades que no estén expresamente concedidas por esta Constitución a los funcionarios federales se entienden reservadas a los estados. No se pierde de vista que, en su anterior conformación, este máximo tribunal había adoptado una posición diversa en la tesis P. C/92, publicada en la Gaceta del Semanario Judicial de la Federación, núm. 60, correspondiente a diciembre de 1992, p. 27, de rubro: «LEYES FEDERALES Y TRATADOS INTERNACIONALES. TIENEN LA MISMA JERARQUÍA NORMATIVA», sin embargo, este Tribunal Pleno considera oportuno abandonar tal criterio y asumir el que considera la jerarquía superior de los tratados incluso frente al derecho federal".

14 Tesis P. IX/2007, Semanario Judicial de la Federación y su Gaceta, t. XXV, abril de 2007, p. 6. "TRATADOS INTERNACIONALES. SON PARTE INTEGRANTE DE LA LEY SUPREMA DE LA UNIÓN Y SE UBICAN JERÁRQUICAMENTE POR ENCIMA DE LAS LEYES GENERALES FEDERALES Y LOCALES. INTERPRETACIÓN DEL ARTÍCULO 133 CONSTITUCIONAL". La 
Mencionamos que al resolver el amparo en revisión 1457/98, el Pleno estableció una serie de juicios complejos sobre nuestro concepto; entre ellos, que la ley suprema de la Unión sólo estaría conformada por la Constitución. En el amparo en revisión 120/2002, la Corte recompuso el contenido de la ley suprema de la Unión y estableció que la Constitución, las leyes generales del Congreso de la Unión y los tratados internacionales que estén de acuerdo con ella, forman parte de ella y que conforman un orden jurídico superior, de carácter nacional y en cuyo interior la Constitución se ubica en el peldaño más alto, seguida de los tratados internacionales y las leyes generales, en ese orden. ${ }^{15}$ Hasta el momento entonces, prevaleció el criterio jerárquico como vertebrador al interior de la ley suprema de la Unión.

\section{EL PARÁMETRO DE REGULARIDAD CONSTITUCIONAL}

\section{La reforma constitucional en materia de derechos humanos de 2011 tuvo como objetivo primordial fortalecer y apuntalar el proceso de constitucio-}

interpretación sistemática del artículo 133 de la Constitución Política de los Estados Unidos Mexicanos permite identificar la existencia de un orden jurídico superior, de carácter nacional integrado por la Constitución federal, los tratados internacionales y las leyes generales. Asimismo, a partir de dicha interpretación, armonizada con los principios de derecho internacional dispersos en el texto constitucional, así como con las normas y premisas fundamentales de esa rama del derecho, se concluye que los tratados internacionales se ubican jerárquicamente debajo de la Constitución federal y por encima de las leyes generales, federales y locales, en la medida en que el Estado mexicano, al suscribirlos, de conformidad con lo dispuesto en la Convención de Viena sobre el derecho de los tratados entre Estados y organizaciones internacionales o entre organizaciones internacionales y además, atendiendo al principio fundamental del derecho internacional consuetudinario «pacta sunt servanda», contrae libremente obligaciones frente a la comunidad internacional que no pueden ser desconocidas invocando normas de derecho interno y cuyo cumplimiento supone, por lo demás, una responsabilidad de carácter internacional”.

15 Tesis P. VIII/ 2007, Semanario Judicial de la Federación y su Gaceta, t. XXV, abril de 2007, p. 6. "SUPREMACÍA CONSTITUCIONAL Y LEY SUPREMA DE LA UNIÓN. INTERPRETACIÓN DEL ARTÍCULO 133 CONSTITUCIONAL. A partir de la interpretación del precepto citado, si aceptamos que las leyes del Congreso de la Unión a las que aquel se refiere, corresponden, no a las leyes federales sino a aquellas que inciden en todos los órdenes jurídicos parciales que integran el Estado mexicano y cuya emisión deriva de cláusulas constitucionales que constriñen al legislador para dictarlas, el principio de supremacía constitucional implícito en el texto del artículo en cita, claramente se traduce en que la Constitución General de la República, las leyes generales del Congreso de la Unión y los tratados internacionales que estén de acuerdo con ella, constituyen «la ley suprema de la Unión», esto es, conforman un orden jurídico superior, de carácter nacional, en el cual la Constitución se ubica en la cúspide y por debajo de ella los tratados internacionales y las leyes generales". 
nalización del derecho internacional de los derechos humanos en términos de provocar una mayor apertura del sistema jurídico mexicano a los derechos humanos de fuente internacional. La reforma abordó temas diversos y generó la modificación de varios artículos constitucionales, ${ }^{16}$ sin embargo, los cambios al artículo 1o. constitucional generaron los impactos más profundos y con efectos directos en el contenido de la ley suprema de la Unión.

Recordemos que hasta el momento la Suprema Corte se había referido a las relaciones que los tratados internacionales — sin distinciones de materia-, debían guardar con el resto de los componentes de la ley suprema de la Unión, pero específicamente con respecto a las leyes. En todas esas resoluciones, los tratados mantuvieron un lugar subordinado a la Constitución. El nuevo artículo 1o. constitucional párrafo primero modificó en parte los términos de dicha relación. El párrafo reformado establece:

En los Estados Unidos Mexicanos todas las personas gozarán de los derechos humanos reconocidos en esta Constitución y en los tratados internacionales de los que el Estado mexicano sea parte, así como de las garantías para su protección, cuyo ejercicio no podrá restringirse ni suspenderse, salvo en los casos y bajo las condiciones que esta Constitución establece.

Esta redacción provocó que ciertos contenidos de tratados internacionales, los derechos humanos, adquieran rango constitucional, estableciendo una excepción a la regla general del carácter infra constitucional y supra legal de los tratados internacionales, regla que sigue manteniendo vigencia con relación al resto de los contenidos de tratados internacionales no relativos a derechos humanos.

De esta forma surgió en el sistema jurídico mexicano un bloque de derechos conformado por los derechos humanos contenidos en la Constitución y aquellos contenidos en tratados internacionales de los que México sea parte y que estén conforme a aquélla. El artículo no refiere únicamente entonces a tratados internacionales sobre derechos humanos. Bajo este criterio, formarán parte del bloque de derechos aquellos derechos huma-

16 Para un estudio pormenorizado de la reforma constitucional y su proceso véase: Carbonell, Miguel y Salazar, Pedro, La reforma constitucional de derechos humanos. Un nuevo paradigma, México, Suprema Corte de Justicia, UNAM, Instituto de Investigaciones Jurídicas, 2012, y García Ramírez, Sergio y Morales Sánchez, Julieta, La reforma constitucional sobre derechos humanos (2009-2022), México, UNAM-Porrúa, 2012. 
nos contenidos o regulados por tratados internacionales, aunque no estén contenidos en tratados de tal naturaleza. ${ }^{17}$ Los derechos humanos de fuente constitucional y aquellos de fuente internacional convocados a la Constitución por el artículo 1o. constitucional, conforman entonces un bloque de constitucionalidad que se ubica en la cúspide del ordenamiento jurídico mexicano y que servirá de parámetro de control constitucional y convencional de las leyes y actos. ${ }^{18}$

El bloque de constitucionalidad tiene diversos significados connotativos por razones espaciales y temporales, ${ }^{19}$ sin embargo, el concepto parece responder a una idea matriz que le permitiría mantener identidad. Rodrigo Uprimny indica que esa idea consistiría en que el bloque de constitucionalidad refiere a la existencia de normas con calidad constitucional que no aparecen directamente en el texto constitucional. ${ }^{20}$ El bloque permitiría canalizar jurídicamente el fenómeno de acuerdo al cual existen normas materialmente constitucionales más allá de las que expresamente ésta reconoce. ${ }^{21}$ Esas normas materialmente constitucionales que integran el bloque de constitucionalidad, son llamadas a integrarse a él por la propia Constitución, tal como sucede en México a partir de la nueva redacción del artículo 1o. constitucional. Esta idea debería ayudar a relativizar el conflicto con el principio de supremacía de la Constitución pues es por su imperio que aquellas normas son llamadas y se integran. ${ }^{22}$ Bidart Campos lo explicó hace tiempo al describir el proceso de reconocimiento de

17 Carmona Tinoco, Jorge Ulises, "La reforma y las normas de derechos humanos", en Carbonell, Miguel y Salazar, Pedro (coords.), La reforma constitucional en materia de derechos humanos. Un nuevo paradigma, cit., p. 45.

18 Ferrer Mac-Gregor, Eduardo, "Interpretación conforme y control difuso de convencionalidad", en Carbonell, Miguel y Salazar, Pedro (coords.), La reforma constitucional en materia de derechos humanos. Un nuevo paradigma, cit., p. 356 . Véase también, Caballero Ochoa, José Luis, "Cláusula de interpretación conforme y el principio propersona”, en Carbonell, Miguel y Salazar, Pedro (coords.), La reforma constitucional en materia de derechos humanos. Un nuevo paradigma, cit., p. 122.

19 Para un análisis pormenorizado del bloque de constitucionalidad véase, Favoreu, Louis y Rubio Llorente, Francisco, El bloque de la constitucionalidad, Madrid, Universidad de Sevilla, Cuadernos Civitas, 1991.

20 Uprimy, Rodrigo, El bloque de constitucionalidad en Colombia, Colombia, Universidad Nacional-ENS, 2005, p. 2, disponible en: www. http://redescuelascsa.com/sitio/ repo/DJS-Bloque_Constitucionalidad(Uprimny).pdf, consultado el 22 de junio de 2016.

21 Idem.

22 Ibidem, p. 3. 
rango constitucional a ciertos tratados internacionales en la reforma constitucional argentina de 1994, al sostener que estos tratados se incorporan al derecho interno, no a la Constitución, fuera de ella pero junto a ella, conformando el bloque de constitucionalidad federal. ${ }^{23}$ En América latina, el bloque de constitucionalidad ha asumido una identidad más específica, como bloque de constitucionalidad de derechos. ${ }^{24}$ Así ha ocurrido en México a partir de la reforma al artículo 1o. constitucional.

Luego de la reforma, la Suprema Corte emitió una serie de importantes pronunciamientos para configurar el bloque constitucional de derechos en nuestro sistema jurídico. La primera determinación importante se tomó en el Expediente Varios 912/2010, al abordar el estudio del parámetro que debían utilizar los jueces para llevar a cabo el control de constitucionalidad y convencionalidad, y resolvió que el parámetro de análisis que debían tomar en cuenta para realizar dicho control se integraría con los derechos humanos de fuente constitucional, los derechos humanos de fuente internacional, la jurisprudencia del poder judicial federal y la jurisprudencia de la Corte Interamericana de Derechos Humanos, entre la que deberían distinguir aquella de carácter vinculante, generada en decisiones en las que México fuere estado demandado y la de carácter orientador, generada en aquellos demás casos en los que México no sea parte. ${ }^{25}$

23 Bidart Campos, Germán, Tratado elemental de derecho constitucional argentino, Nueva edición ampliada y actualizada, t. III, El derecho internacional de los derechos humanos y la reforma constitucional de 1994, Buenos Aires, Ediar, 1995, p. 285.

24 Nogueira Alcalá, Humberto, "El bloque constitucional de derechos en Chile. El parámetro de control y consideraciones comparativas con Colombia y México: doctrina y jurisprudencia”, Estudios Constitucionales, Chile, año 13, núm. 2, 2015, pp. 301-350.

25 Tesis P. LXVIII/2011 (9a), Semanario Judicial de la Federación y su Gaceta, Libro III, diciembre de 2011, t. 1, p. 551. "PARÁMETRO PARA EL CONTROL DE CONVENCIONALIDAD EX OFFICIO EN MATERIA DE DERECHOS HUMANOS. El mecanismo para el control de convencionalidad ex officio en materia de derechos humanos a cargo del Poder Judicial debe ser acorde con el modelo general de control establecido constitucionalmente. El parámetro de análisis de este tipo de control que deberán ejercer todos los jueces del país, se integra de la manera siguiente: a) todos los derechos humanos contenidos en la Constitución federal (con fundamento en los artículos 1o. y 133), así como la jurisprudencia emitida por el Poder Judicial de la Federación; b) todos los derechos humanos contenidos en tratados internacionales en los que el Estado mexicano sea parte; c) los criterios vinculantes de la Corte Interamericana de Derechos Humanos derivados de las sentencias en las que el Estado mexicano haya sido parte, y d) los criterios orientadores de la jurisprudencia y precedentes de la citada Corte, cuando el Estado mexicano no haya sido parte". 
La Suprema Corte introdujo un término cercano al bloque de constitucionalidad, lo llamó "parámetro de análisis", término que tiene una connotación más procesal. ${ }^{26}$

Tiempo después al resolver una serie de amparos, la Primera Sala de la Suprema Corte interpretó el artículo 1o. constitucional reformado y determinó las normas de derechos humanos de fuente constitucional y de fuente internacional son "normas supremas del ordenamiento jurídico y fuentes primigenias", de modo que comprendió al bloque de derechos como un complejo normativo que se supra ordena al resto del ordenamiento. En la segunda parte de la tesis, abordó el tema de las posibles diferencias o eventuales conflictos al interior del bloque de derechos. Cuando existan diferencias de alcance y protección entre los derechos de fuente constitucional y aquellos de fuente internacional, el derecho aplicable será determinado mediante la operación del principio propersona que indica aplicar el derecho que brinde mayor protección o bien "menor restricción". Esta última cuestión es fundamental; la primera sala comprendió el verdadero sentido de la reforma y la decisión política fundamental adoptada por el poder reformador, consistente en dejar atrás el criterio jerárquico y proponer que los derechos humanos de fuente internacional se integren de manera armónica. ${ }^{27}$ Además, de manera acertada, entendió al principio propersona

26 Astudillo, César, "El bloque y el parámetro de constitucionalidad en la interpretación de la Suprema Corte de Justicia de la Nación", en Carbonell, Miguel et al. (coords.), Estado constitucional, derechos humanos, justicia y vida universitaria. Estudios en homenaje a Jorge Carpizo. Estado constitucional, t. IV, vol. I, México, UNAM, Instituto de Investigaciones Jurídicas, 2015, pp. 119 y ss.

27 Tesis 1a./J. 107/2012 (10a), Semanario Judicial de la Federación y su Gaceta, Libro XIII, octubre de 2012, t. 2, p. 799. "PRINCIPIO PRO PERSONA. CRITERIO DE SELECCIÓN DE LA NORMA DE DERECHO FUNDAMENTAL APLICABLE. DE conformidad con el texto vigente del artículo 1o. constitucional, modificado por el decreto de reforma constitucional publicado en el Diario Oficial de la Federación el 10 de junio de 2011, en materia de derechos fundamentales, el ordenamiento jurídico mexicano tiene dos fuentes primigenias: a) los derechos fundamentales reconocidos en la Constitución Política de los Estados Unidos Mexicanos y b) todos aquellos derechos humanos establecidos en tratados internacionales de los que el Estado mexicano sea parte. Consecuentemente, las normas provenientes de ambas fuentes son normas supremas del ordenamiento jurídico mexicano. Esto implica que los valores, principios y derechos que ellas materializan, deben permear en todo el orden jurídico, obligando a todas las autoridades a su aplicación y en aquellos casos en que sea procedente, a su interpretación. Ahora bien, en el supuesto de que un mismo derecho fundamental sea reconocido en las dos fuentes supremas del ordenamiento jurídico, a saber, la Constitución y los tratados internacionales, la elección de la norma que será aplicable — en materia de derechos humanos—, atenderá a criterios 
en toda su extensión. Este principio tiene dos expresiones, indica Mata Quintero, una positiva y otra negativa, ${ }^{28}$ la expresión positiva permite el despliegue del principio en el sentido de elegir la norma o la interpretación más amplia cuando se trate de reconocer y proteger derechos, la expresión negativa determina que se debe elegir la norma o interpretación más restrictiva cuando se trate de restringirlos. ${ }^{29}$ Ambas expresiones conforman el contenido del principio. La sala asumió el principio en completitud. Con el tiempo, el principio será cercenado.

La siguiente resolución importante fue tomada al resolver la Acción de Inconstitucionalidad 155/2007. En ella, se indicó que en él Varios 912/2010, se estableció la existencia de un parámetro de regularidad constitucional a partir del cual se determinaría la validez de las normas del orden jurídico mexicano y que a su vez serviría como catálogo normativo para los jueces. ${ }^{30}$ Sin embargo, lo más interesante de la decisión tomada en esta acción consistió en ofrecer un buen ejemplo de aplicación del principio propersona para la selección de la norma aplicable tratándose de derechos. En esta acción, se impugnó la validez de diversos artículos de la Ley de Prevención de Adicciones del Estado de Yucatán que permitían que autoridades administrativas impusieran sanciones consistentes en trabajos forzosos a los infractores de la ley, por ser contrarios al artículo 5o. constitucional. Para la composición del parámetro de control, la Corte identificó que además del artículo 5o. ya mencionado, a partir de 2008, el artículo 21 constitucional permitía la imposición de sancio-

que favorezcan al individuo o a lo que se ha denominado principio propersona, de conformidad con lo dispuesto en el segundo párrafo del artículo 1o. constitucional. Según dicho criterio interpretativo, en caso de que exista una diferencia entre el alcance y la protección reconocida en las normas de estas distintas fuentes, deberá prevalecer aquella que represente una mayor protección para la persona o que implique una menor restricción. En esa lógica, el catálogo de derechos fundamentales, no se encuentra limitado a lo prescrito en el texto constitucional, sino que también incluye a todos aquellos derechos que figuran en los tratados internacionales ratificados por el Estado mexicano".

28 Mata Quintero, Gerardo, "El principio propersona: la fórmula del mejor derecho", Cuestiones Constitucionales, Revista Mexicana de Derecho Constitucional, núm. 39, julio-diciembre de 2018, p. 210.

29 Pinto, Mónica, "El principio pro homine. Criterios de hermenéutica y pautas para la regulación de los derechos humanos", en Abregú, Martis y Courtis, Christian (comps.), La aplicación de los tratados sobre derechos humanos por los tribunales locales, Buenos Aires, Editores del Puerto, 1997, p. 163.

30 Acción de Inconstitucionalidad 155/2007, Diario Oficial de la Federación, 30 de octubre de 2012, segunda sección, pp. 42 y 43. 
nes por autoridad administrativa ante el supuesto de incumplimientos de reglamentos gubernativos y de policía. Por otro lado, el Convenio 29 de la Organización General del Trabajo, el Pacto Internacional de Derechos Civiles y Políticos y la Convención Americana de Derechos Humanos, resultaban aplicables y estos tratados, al ser interpretados en su conjunto, ofrecían una mejor protección que la norma constitucional al determinar que los trabajos forzosos sólo podían imponerse con el carácter de pena y mediante decisión judicial. La Corte entendió que esa elección era la que exigía el artículo 1o. constitucional. ${ }^{31}$ Sin embargo, y a pesar de esta decisión, las divergencias entre la primera y la segunda salas al respecto de la conformación y operación del parámetro de regularidad constitucional, se hicieron cada vez más evidentes. Estas divergencias se observaban también en las determinaciones de los tribunales inferiores. La oportunidad para fijar un criterio estable al respecto se daría con ocasión de resolver la Contradicción de tesis 293/2011.

Dos fueron los temas a resolver en la contradicción: la posición jerárquica de los tratados internacionales en materia de derechos humanos y el valor de la jurisprudencia emitida por la Corte Interamericana de Derechos Humanos, ${ }^{32}$ y tres fueron las determinaciones tomadas; primero, se confirmó el criterio previamente establecido en orden a reconocer que los derechos humanos de fuente constitucional e internacional conforman un parámetro de regularidad constitucional y que no se relacionan en términos jerárquicos sino armónicos y en caso de diferencias o antinomias, éstas se resolverán de acuerdo a lo que determine la operación del principio pro persona; segundo, se estableció una excepción a la regla anterior que se configuraría cuando en la Constitución se establezca una restricción a un derecho humano y que ésta debería prevalecer sobre lo que determine la norma internacional, ${ }^{33}$ y tercero, que los criterios jurisprudenciales de

31 Para un análisis del caso véase, Cossío, José Ramón et al., La construcción de las restricciones constitucionales a los derechos humanos, México, Porrúa, 2015, pp. 15 y ss.

32 Contradicción de tesis 293/2011, Suprema Corte de Justicia de la Nación, Engrose, p. 26.

33 Tesis P./J 20/2014 (10a), Gaceta del Semanario Judicial de la Federación, libro 5, abril de 2014, t. 1, p. 202. "DERECHOS HUMANOS CONTENIDOS EN LA CONSTITUCIÓN Y EN LOS TRATADOS INTERNACIONALES, CONSTITUYEN EL PARÁMETRO DE CONTROL DE REGULARIDAD CONSTITUCIONAL, PERO CUANDO EN LA CONSTITUCIÓN HAYA UNA RESTRICCIÓN EXPRESA AL EJERCICIO DE AQUÉLLOS, SE DEBE ESTAR A LO QUE ESTABLECE EL TEXTO CONSTITUCIONAL. El primer párrafo del artículo 1o. constitucional reconoce un conjunto de derechos humanos cuyas fuentes son la Constitución y los tratados in- 
la Corte Interamericana de Derechos Humanos establecidos en casos en los que México no hubiere sido parte, tendrán carácter vinculante, modificando así el criterio sentado en el Varios 912/2010, a partir del cual se les había asignado carácter orientador. ${ }^{34}$

Decidir con relación a las restricciones constitucionales implicó un significativo retroceso en el camino iniciado con la reforma en materia de

ternacionales de los cuales el Estado mexicano sea parte. De la interpretación literal, sistemática y originalista del contenido de las reformas constitucionales de 6 y 10 de junio de 2011, se desprende que las normas de derechos humanos, independientemente de su fuente, no se relacionan en términos jerárquicos, entendiendo que derivado de la parte final del primer párrafo del citado artículo 1o., cuando en la Constitución haya una restricción expresa al ejercicio de los derechos humanos, se deberá estar a lo que indica la norma constitucional, ya que el principio que le brinda supremacía comporta el encumbramiento de la Constitución como norma fundamental del orden jurídico mexicano, lo que a su vez implica que el resto de las normas jurídicas deben ser acordes con la misma, tanto en el sentido formal como material, circunstancia que no ha cambiado; lo que sí ha evolucionado a raíz de las reformas constitucionales en comento, es la configuración del conjunto de normas jurídicas respecto de las cuales puede predicarse dicha supremacía en el orden jurídico mexicano. Esta transformación se explica por la ampliación del catálogo de derechos humanos previsto dentro de la Constitución Política de los Estados Unidos Mexicanos, el cual evidentemente debe calificarse como parte del conjunto normativo que goza de esta supremacía constitucional. En este sentido, los derechos humanos, en su conjunto, constituyen el parámetro de control de regularidad constitucional, conforme al cual debe analizarse la validez de las normas y actos que forman parte del orden jurídico mexicano".

34 Tesis P./J 21/2014 (10a), Gaceta del Semanario Judicial de la Federación, libro 5, abril de 2014, t. 1, p. 204. "JURISPRUDENCIA EMITIDA POR LA CORTE INTERAMERICANA DE DERECHOS Humanos. ES VINCULANTE PARA LOS JUECES MEXICANOS SIEMPRE QUE SEA MÁS FAVORABLE A LA PERSONA. Los criterios jurisprudenciales de la Corte Interamericana de Derechos Humanos, con independencia de que el Estado mexicano haya sido parte en el litigio ante dicho tribunal, resultan vinculantes para los jueces nacionales al constituir una extensión de la Convención Americana sobre Derechos Humanos, toda vez que dichos criterios determinan el contenido de los derechos humanos establecidos en ese tratado. La fuerza vinculante de la jurisprudencia interamericana se desprende del propio mandato establecido en el artículo 1o. constitucional, pues, por principio propersona, obliga a los jueces nacionales a resolver cada caso atendiendo a la interpretación más favorable a la persona. En cumplimiento de este mandato constitucional, los operadores jurídicos deben atender a lo siguiente: i) cuando un criterio se haya emitido en un caso en el que el Estado mexicano no haya sido parte, la aplicación del precedente al caso específico debe determinarse con base en la verificación de la existencia de las mismas razones que motivaron el pronunciamiento, ii) en todos los casos en que sea posible, debe armonizarse la jurisprudencia interamericana con la nacional y, iii) de ser imposible la armonización, debe aplicarse el criterio que resulte más favorable para la protección de los derechos humanos".

Esta obra está bajo una Licencia Creative Commons

Atribución-NoComercial-SinDerivar 4.0 Internacional, IIJ-UNAM. 
derechos humanos. A continuación, se indican las razones por las cuales consideramos que la decisión es equivocada.

En primer término, establecer la prevalencia de las restricciones constitucionales de manera apriorística y general, implica reincorporar el principio jerárquico para resolver las diferencias en el interior del bloque de derechos. Esta decisión contradice el método establecido por el artículo 10. que determina una relación no jerarquizada y dinámica para favorecer la aplicación del mejor derecho al caso.

Eventualmente los derechos admiten restricciones y no todas ellas serán inconvencionales o inconstitucionales, sin embargo, la decisión de la Corte no distingue y declara que todas ellas, siempre prevalecerán y habrá entonces que incluir claro, aquellas que sean efectivamente contrarias al derecho convencional. Esta determinación contradice de manera frontal los artículos 1o., 20. y 29 a) de la Convención Americana. Los artículos 10. y 2o. establecen las obligaciones genéricas de respetar los derechos de la Convención y adoptar medidas internas para hacerlos efectivos, obligaciones que se violarían si por medio de la Constitución se establecen o mantienen restricciones a derechos por debajo de los mínimos convencionales y son aplicadas por parte de los jueces de cada estado. Además, el artículo 29 inciso "a" establece la prohibición de interpretar normas de la Convención para limitar los derechos más allá de los límites convencionales. Es decir, que si bien la Convención admite en el artículo 30 que los Estados pueden establecer restricciones a los derechos, ello no habilita restricciones por debajo del mínimo convencional. Por estas razones la decisión es inconvencional; además, compromete potencialmente la responsabilidad internacional del Estado al obligar a los jueces a aplicar las restricciones constitucionales a pesar de su inconvencionalidad. La Segunda Sala tuvo ocasión de dar una suerte de respuesta a este argumento. Al resolver el amparo en revisión 6065/2014, la Sala pretendió justificar la jurisprudencia comentada al establecer que las restricciones que pudiera establecer el Constituyente tienen sustento convencional en los artículos 30 y 32.2 de la Convención Americana sobre Derechos Humanos, que habilitan a los Estados a establecer restricciones cuando ellas se justifiquen en razones de interés general además de resultar ineludibles por razones de seguridad y las justas exigencias del bien común en una sociedad democrática. ${ }^{35}$ Ya

35 Tesis 2a. CXXVIII/2015, Gaceta del Semanario Judicial de la Federación, Libro 24, noviembre de 2015, t. 2, p. 1299. 
mencionamos la contradicción entre esta interpretación y lo establecido por el artículo 29 de la Convención; habría que agregar que las restricciones están sujetas a ciertas condiciones, entre ellas, que sean necesarias y proporcionales; además, se debe garantizar la posibilidad de demostrar que ellas responden a estas notas y que persiguen los objetivos convencionalmente establecidos. En tal sentido, las críticas anteriores se sostienen, pues la decisión de la Sala más bien inhibe el ejercicio interpretativo necesario para determinar la validez de la restricción. De manera expresa determinó que la decisión tomada en la Contradicción de tesis 293/2011, implica no dar lugar a juicio de ponderación posterior.

En tercer lugar, la decisión desconoció el propio artículo 1o. constitucional, que establece el principio propersona para determinar el derecho aplicable al caso cuando tanto la Constitución como la Convención regulen el derecho. La aplicación del principio no se ve afectada por la mención que el párrafo primero del artículo 1o. hace de las restricciones que la Constitución establezca, más allá que se considere que el párrafo primero hace referencia al régimen del artículo 29 constitucional, o bien, a todas las restricciones esparcidas por la Constitución. El principio propersona no sólo fue excluido inconstitucionalmente, sino que además resultó cercenado en su comprensión, al eliminarse una de sus expresiones, aquella restrictiva que debe operar al interpretar restricciones y eliminar las restricciones más restrictivas. Por estas razones, la decisión resultó también inconstitucional.

En la decisión se observa además una comprensión imprecisa acerca de la estructura y contenido de las normas de derechos humanos. Robert Alexy explica que es posible distinguir entre los derechos y sus restricciones, es decir, "el derecho en sí", "que no está restringido" y el derecho que queda luego de aplicar las restricciones al derecho en sí, es decir, el "derecho restringido". ${ }^{36}$ El derecho restringido, es expresado en la "norma completa de derecho fundamental" ${ }^{37}$ que tendrá su lado negativo, constituido por la restricción, y su lado positivo, conformado por el supuesto de hecho del derecho fundamental y el del ámbito ius fundamental protegido. ${ }^{38}$ Cuando se afirma que los derechos de fuente constitucional y de fuente internacional forman el parámetro de regularidad constitucional, la

\footnotetext{
36 Alexy, Robert, Teoría de los derechos fundamentales, trad. de Ernesto Garzón Valdés, Madrid, Centro de Estudios Constitucionales, 2002, p. 268.

37 Ibidem, p. 277.

38 Ibidem, p. 292.
}

Esta obra está bajo una Licencia Creative Commons

Atribución-NoComercial-SinDerivar 4.0 Internacional, IIJ-UNAM. 
expresión sólo tiene sentido si la utilizamos para evocar lo que en términos de Alexy denominamos norma completa de derecho fundamental, es decir, el derecho y sus restricciones (delimitaciones, configuraciones, etcétera). Sólo esta comprensión permite además el desenvolvimiento completo del principio propersona y su operación, no nada más para elegir el derecho más amplio, sino incluso para descartar la restricción más aguda. En la decisión, la Corte procede a desagregar los derechos de sus restricciones para luego aplicar de manera selectiva las restricciones constitucionales, aunque sean más restrictivas. ${ }^{39}$

El segundo asunto discutido en la contradicción que estamos comentando tuvo que ver con la revisión del criterio establecido en el expediente Varios 912/2010 referido al carácter orientador asignado a las sentencias de la Corte IDH en las que el Estado mexicano no haya sido parte. En un sentido, la decisión anterior no era del todo respetuosa con las pretensiones del sistema interamericano y la comprensión de la Corte IDH para el ejercicio del control de convencionalidad, pues de acuerdo a sus decisiones, dicho control debía considerar como parámetro las interpretaciones que la Corte IDH hubiera vertido y las interpretaciones a las que refiere, son las vertidas tanto en sentencias en las que el Estado sea parte y aquellas en los que no lo sea. La Suprema Corte decidió entonces modificar el criterio y determinar que

...como resultado de nuevas reflexiones, y con motivo de la nueva integración de este Tribunal Pleno, debe considerarse que esta fuerza vinculante de los criterios interpretativos contenidos en sentencias interamericanas debe extenderse a aquellas dictadas en casos en los que el Estado mexicano no haya sido parte". ${ }^{40}$

Esta decisión, si bien correcta, leída junto a la referida a las restricciones, incrementará el grado de contradicción de la decisión con el sistema de derechos.

39 Para analizar los problemas derivados de no comprender las relaciones entre derechos y restricciones o entre ámbito y alcance de los derechos, véase también: Ortega García, Ramón, "El enfoque restrictivo de los derechos humanos: comentarios a la contradicción de tesis 293/2011", Cuestiones Constitucionales, Revista Mexicana de Derecho Constitucional, núm. 32, enero-junio de 2015, pp. 287 y ss.

40 Contradicción de tesis 293/2011 engrose, p. 80. 
En resumen, la decisión de la Corte en cuanto a las restricciones adolece de varios defectos que Francisca Pou resumió al afirmar que la decisión es incompleta, vaga, inestable y juristocéntrica. Incompleta pues no aclara absolutamente nada respecto a otras fuentes del derecho internacional de los derechos humanos que deberían ser reconocidas como integrantes del parámetro de regularidad constitucional, por ejemplo las opiniones consultivas de la Corte Interamericana, a las cuales el alto tribunal interamericano ya les atribuyó carácter vinculante; ${ }^{41}$ vaga porque la referencia a restricciones expresas es sumamente imprecisa y más en este caso, en el cual la Corte nada dice sobre su aplicación. Efectivamente como también ha señalado Fernando Silva, normalmente el alcance de las restricciones en general se define en su aplicación, la que debe estar rodeada de otros derechos cuyo respeto condiciona la validez de la aplicación de la restricción; ${ }^{42}$ inestable pues considerando la cantidad de votos concurrentes y las inconsistencias entre cada uno de ellos y las razones del proyecto, difícilmente se pueda considerar que existe allí una decisión en sentido fuerte. Y por último, juristocéntrica por la centralidad concedida a lo que la Corte resuelva en cada caso. ${ }^{43}$

¿Qué opciones tienen los jueces y la propia Suprema Corte para llevar a cabo las labores de control de constitucionalidad y convencionalidad sobre la base de semejante contradicción al interior del parámetro de control? Comencemos por el resto de los jueces. La determinación de la Suprema Corte se presenta de manera algo irresistible pues su enunciado es categórico. Una primera opción para los operadores jurídicos podría consistir - como apuntó Fernando Silva-, en verificar que, en la aplicación de la restricción, se respeten los demás derechos que deben acompañar esa aplicación. Sin embargo, ese trabajo no tiene que ver con la verificación de la convencionalidad de la restricción en sí. Más allá de eso, la forma de su enunciación pareciera inhibir además cualquier juicio de ponderación que

\footnotetext{
41 Corte Interamericana de Derechos Humanos, OC- 21/14 de 19 de agosto de 2014.

42 Silva García, Fernando, "Derechos humanos y restricciones constitucionales: ¿reforma constitucional del futuro vs. interpretación constitucional del pasado? (comentario a la C.T. 293/2011 del Pleno de la SCJN)", Cuestiones Constitucionales. Revista Mexicana de Derecho Constitucional, México, núm. 30, enero-junio 2014.

43 Pou, Francisca, "Lo que quisiera que la Corte hiciera por mí: lealtad constitucional y justicia dialógica en la aplicación de la CT 293/2011”, en Caballero Ochoa, José Luis y Sánchez Gil, Rubén (coords.), Derechos constitucionales e internacionales, México, Tirant lo Blanch, 2018, p. 599.
} 
los jueces inferiores quisieran realizar al momento de aplicar la restricción constitucional con respecto a otros principios. Por supuesto, quedaría fuera la ponderación con otras normas de fuente internacional, aunque podría considerarse abierta la posibilidad de realizar una ponderación con respecto a otras normas constitucionales. Sin embargo, esta opción también parece desplazada, por lo menos en opinión de la Segunda Sala, cuando se resolvió la tesis 2a. CXXVIII/2015 en la cual, recordemos, determinó que la decisión sobre las restricciones no da lugar a ninguna ponderación.

Cabría preguntarse también qué podría hacer un juez mexicano ante una restricción constitucional declarada inconvencional en una sentencia por la Corte Interamericana de Derechos Humanos. Una opción hubiera sido que en un supuesto así, el juez mexicano podría inaplicar la restricción debido al carácter vinculante de la sentencia interamericana. Sin embargo, esta posibilidad quedó vedada cuando la Suprema Corte resolvió el expediente Varios 1396/2011, que paradójicamente se abrió a trámite para resolver la forma de dar cumplimiento a las sentencias condenatorias de la Corte Interamericana de Derechos Humanos recaídas en los casos Fernández Ortega ${ }^{44}$ y Rosendo Cantú ${ }^{45}$ contra México. En este caso, la Corte determinó que si bien las sentencias de la Corte Interamericana de Derechos Humanos no pueden ser escrutadas por la Suprema Corte de Justicia de la Nación en cuanto a si son correctas o no, cuando alguno de los deberes del fallo interamericano implique desconocer una restricción constitucional (supuesto de control convencional sobre la Constitución), ésta deberá prevalecer. ${ }^{46}$ De esta forma, la Corte profundizó el error cometido al resolver la contradicción 293/2011 y así, los restantes componentes del parámetro de regularidad constitucional se jerarquizan independientemente de su inconvencionalidad.

En definitiva, los jueces inferiores están en problemas. Cuando deban resolver un caso en el que esté en juego una restricción constitucional, no podrán analizar la convencionalidad de la restricción, tampoco ponderarla con respecto a otros principios, solo podrán aplicarla. De esta forma, si la restricción es inconvencional, comprometerán la responsabilidad interna-

\footnotetext{
44 Corte IDH, caso Fernández Ortega y otros vs. México, Excepciones preliminares, fondo, reparaciones y costas, sentencia del 30 de agosto de 2010, serie C, núm. 215.

45 Corte IDH, caso Rosendo Cantú y otra vs. México, Excepciones preliminares, fondo, reparaciones y costas, sentencia del 31 de agosto de 2010, Serie C, núm. 216.

46 Tesis P.XVI/2015 (10a.), Gaceta del Semanario Judicial de la Federación, libro 22, septiembre de 2015, t. I, p. 237.
} 
cional del Estado. Si existiera una sentencia de la Corte Interamericana en la que se estableciera la inconvencionalidad de la restricción, deberán desobedecerla.

Ahora bien, y ¿qué podrán hacer de acá en más las Salas de la Corte y el Tribunal Pleno? Pocos meses después, la Segunda Sala estableció con carácter de jurisprudencia los siguientes criterios: primero: que las restricciones constitucionales a los derechos deben aplicarse sin posibilidad de realizar ponderación alguna, segundo: que las restricciones pueden interpretarse de un modo más favorable, tercero, que el intérprete constitucional, especialmente la Suprema Corte, al hacer prevalecer una restricción debe practicar una interpretación más favorable y sistemática, delimitando su alcance según lo establecido por otras disposiciones de la Constitución. ${ }^{47}$ En primer término la Corte ratifica la regla: en nuestro sistema prevalecen las restricciones constitucionales a los derechos por sobre el derecho convencional. En segundo lugar, insiste con esa suerte de regla preventiva sobre la imposibilidad absoluta de realizar juicio de ponderación alguno. Sin embargo, a continuación, asume los excesos de esta regla e intenta suavizar sus efectos. Comienza por afirmar que esta regla es compatible con una interpretación más favorable que el intérprete constitucional debería realizar para no aplicar la restricción sin más — de manera indiscriminada afirma la Sala_-, con la finalidad de delimitar sus alcances

47 Tesis 2a /J. 163/2017, Semanario Judicial de la Federación, libro 49, diciembre de 2017, t. 1, p. 487. "RESTRICCIONES CONSTITUCIONALES AL GOCE Y EJERCICIO DE LOS DERECHOS Y LIBERTADES. SU CONTENIDO NO IMPIDE QUE LA SUPREMA CORTE DE JUSTICIA DE LA NACIÓN LAS INTERPRETE DE LA MANERA MÁS FAVORABLE A LAS PERSONAS, EN TÉRMINOS DE LOS PROPIOS POSTULADOS CONSTITUCIONALES. Conforme a lo resuelto por el Pleno de la Suprema Corte de Justicia de la Nación en la contradicción de tesis 293/2011, las restricciones constitucionales al goce y ejercicio de los derechos y libertades prevalecen sobre la norma convencional, sin dar lugar a emprender algún juicio de ponderación posterior; sin embargo, nada impide que el intérprete constitucional, principalmente la Suprema Corte de Justicia de la Nación, al hacer prevalecer una restricción o limitación constitucional, también practique un examen de interpretación más favorable en la propia disposición suprema, delimitando sus alcances en forma interrelacionada con el resto de las disposiciones del mismo texto constitucional. En efecto, no porque el texto de la Constitución Política de los Estados Unidos Mexicanos deba prevalecer, su aplicación ha de realizarse de manera indiscriminada, lejos de ello, el compromiso derivado de lo resuelto en la aludida contradicción de tesis privilegia un ejercicio hermenéutico que lleve al operador jurídico competente a que sin vaciar de contenido la disposición restrictiva, ésta sea leída de la forma más favorable posible, como producto de una interpretación sistemática de todos sus postulados. 
con respecto al resto de la Constitución. Lo que postula la Sala es la necesidad de interpretar las restricciones de modo que, de existir diversos resultados interpretativos, se deba preferir aquel que resulte más favorable a la persona, es decir, propone aquí habilitar la operación reducida del principio pro persona; además, postula que con tal ejercicio interpretativo se procurará articular esa restricción con el resto de la Constitución, esto es, realizar una interpretación sistemática. Habría que recordar que el resto de la Constitución incluye los derechos humanos de fuente internacional, traídos por el artículo 1o., por lo que esta determinación parece algo contradictoria con la decisión tomada en la contradicción de tesis 293/2011 acerca de la prevalencia de las restricciones. Tal resultado interpretativo sólo podría lograrse frente a restricciones convencionalmente aceptables, con relación al resto, esta jurisprudencia podría estar postulando un trabajo interpretativo de resultado incierto. Lo cierto es que la operación dentro del parámetro de control resultará sumamente complicada para los operadores jurídicos. Al referir al "intérprete constitucional" parece extender esta posibilidad interpretativa a todos los jueces, pero lo hace al parecer tratando de desincentivar tal actividad, o bien, incentivando a que los órganos jurisdiccionales que tengan competencia soliciten a la Suprema Corte que ejerza eventualmente la facultad de atracción, pero ésta no será opción para los jueces comunes, quienes se verán eventualmente conminados por la fuerza de la jurisprudencia, a tomar decisiones inconvencionales e inconstitucionales. Esta opción, si bien correcta, parece algo descafeinada considerando las opciones brindadas por el artículo 1o. constitucional que han sido fuertemente disminuidas por la decisión de la Corte.

La Suprema Corte tendría otra opción. Francisca Pou sostiene una tesis interesante para explicar aquello que la Corte mexicana podría hacer con la contradicción de tesis 293/2011. Sostiene que otra de las características de esta sentencia es su carácter contemporizador y leal con la Constitución, pero por invisibilizar o minimizar las incoherencias, éstas se terminaron haciendo más patentes. ${ }^{48}$ Antes esto, ¿qué otra opción existe entre por un lado el seguimiento callado de la tesis de la 293/2011 o de su mejor versión descafeinada de acompañarla con la interpretación sistemática y por el otro, la opción más radical que consistiría en declarar la inconstitucionalidad de las restricciones inconstitucionales e inconvencionales si ello se pudiera? La opción sería recurrir a un comportamiento dialógico

48 Pou, Francisca, op. cit., pp. 499 y ss.

Esta obra está bajo una Licencia Creative Commons Atribución-NoComercial-SinDerivar 4.0 Internacional, IIJ-UNAM. 
consistente en evidenciar y señalar las contradicciones para de ese modo provocar la reacción de los otros poderes. ${ }^{49}$ En su versión más fuerte, este ejercicio de justicia dialógica se podría activar con pedidos a los poderes políticos en los puntos resolutivos de las sentencias para que modifiquen la Constitución y, por ejemplo, procedan a suprimir la restricción. Este tipo de trabajo contribuiría también a generar debate público sobre el tema y a la larga mejoraría el nivel de protección de los derechos. ${ }^{50}$ En general coincidimos con la propuesta, sin embargo, nos cuesta identificar que la decisión sobre las restricciones sea producto de las lealtades de la Corte a la Constitución, un comportamiento igualmente leal, pero al artículo 1o., le podría haber llevado a establecer una decisión que restrinja la operatividad de las restricciones constitucionales inconvencionales. En todo caso, pareciera que la lealtad de la Corte fue a la Constitución antes de la reforma, o bien, a la Constitución como ley suprema antes de la conformación del bloque de derechos o parámetro de regularidad constitucional. La lealtad a la nueva "Constitución de los derechos", debería haber conducido a una decisión diferente. Podríamos asumir también que la lealtad de la Corte es a las decisiones democráticas que, a través de los órganos competentes, se decide establecer ciertas restricciones inconvencionales en la Constitución, sin embargo, ese mismo poder decidió establecer en el artículo primero el bloque de derechos y en tal sentido, detrás del artículo 1o., el criterio armonizador y el principio propersona, hay también una decisión democrática que merece deferencia. Amén de este comentario, creo que la propuesta de Pou es relevante pues asumiendo que la Suprema Corte se anime a modificar su criterio y proceder por ejemplo a inaplicar restricciones inconvencionales, esto tendría como efecto el admitir la existencia de normas constitucionales inconstitucionales. La única vía para solucionar esa clase de antinomias hoy por hoy es que el poder reformador actúe y modifique esas normas. La Corte podría ayudar a activar ese proceso.

\section{EL PARÁMETRO DE REGULARIDAD CONSTITUCIONAL EN LA LEY SUPREMA DE LA UNIÓN}

En el proceso de elaboración de propuestas para la reforma constitucional de 2011, se pensó en modificar el artículo 133 constitucional para recono-

\footnotetext{
49 Ibidem, p. 615.

50 Ibidem, p. 614.
}

Esta obra está bajo una Licencia Creative Commons

Atribución-NoComercial-SinDerivar 4.0 Internacional, IJJ-UNAM. 
cer jerarquía constitucional a los tratados internacionales sobre derechos humanos. ${ }^{51}$ Sin embargo, explica Caballero Ochoa, comenzaron a prevalecer las opiniones tendentes a establecer la jerarquía constitucional de los derechos humanos de fuente internacional en el artículo 1o., en el cual se condensan las principales disposiciones constitucionales sobre la dimensión de los derechos humanos en el sistema jurídico mexicano. ${ }^{52}$ Amén de esta cuestión de orden, se procuró evitar que el artículo 133 siga generando divisiones; mantener su carácter de sistema de fuentes, dar a los derechos humanos de fuente internacional autonomía como derecho no producido por el ordenamiento interno ${ }^{53} \mathrm{y}$, creemos, mantener alejados a los derechos humanos de la gradación jerárquica a la que hubieran ingresado de haber sido incorporados en el artículo 133 y, por tanto, en el ámbito del concepto ley suprema de la Unión. Tomando en cuenta los increíbles problemas interpretativos que este artículo ha generado a lo largo de los años, no parece haber sido una mala estrategia, aunque la Suprema Corte se encargó, como hemos analizado, de reinsertar la discusión en clave jerárquica.

De todas formas, el concepto ley suprema de la Unión y así el artículo 133, ha sido modificado por la aparición del bloque de derechos establecido en el artículo 1o. constitucional y conceptualizado por la Suprema Corte como parámetro de regularidad constitucional.

Los derechos humanos de fuente constitucional y los provenientes del derecho internacional, conforman un bloque en cuyo interior no existen jerarquías y las relaciones entre esos derechos se deberían resolver mediante los criterios de interpretación conforme y principio propersona. Este bloque de derechos que se integra en términos armónicos y no jerárquicos con el resto del ordenamiento no renuncia a su carácter prevalente ante ciertas circunstancias, como cuando se pretenden vulnerar los límites mínimos desde allí establecidos. En esos casos, el bloque reclama supra ordenación frente a todo el ordenamiento jurídico. Se podría afirmar entonces que el bloque de derechos impregna todo el ordenamiento y se integra con normas que son supremas por mandato constitucional. La ley suprema de la Unión de esta manera se completa por mandato constitucional, con el parámetro de regularidad constitucional y convencional.

\footnotetext{
51 Caballero Ochoa, José Luís, op. cit., p. 107.

52 Ibidem, p. 108.

53 Ibidem, p. 109.
} 


\section{CONCLUSIONES}

Los profundos cambios motivados por la reforma constitucional en materia de derechos humanos de junio de 2011, requieren de una puesta a punto de conceptos fundamentales de nuestra Constitución. Es el caso del concepto "ley suprema de la Unión" del artículo 133, que, si bien no fue modificado en su texto, ha resultado fuertemente impactado por los cambios operados en el artículo 1o. constitucional, y demanda una nueva lectura que permita ponerlo en consonancia con éste. Específicamente, nos hemos propuesto determinar el lugar que ocupa el parámetro de regularidad constitucional identificado por la Suprema Corte de Justicia de la Nación a partir de su labor interpretativa del artículo 1o. constitucional, en el complejo entramado denominado ley suprema de la Unión. Con apoyo en las principales determinaciones de la Corte, hemos concluido que el nuevo parámetro resulta identificable como un bloque de derechos y que ocupa un lugar preeminente en el marco de la ley suprema de la Unión. Asimismo, y respecto a la articulación de las relaciones entre los componentes constitucionales y convencionales del bloque, persisten ideas que provocan inconsistencias y contradicciones. Específicamente, las decisiones de la Suprema Corte de Justicia de la Nación en torno a la prevalencia de las restricciones constitucionales expresas a los derechos y su persistencia acerca de la inaplicabilidad de las sentencias de la Corte Interamericana en las que se declare la inconvencionalidad de restricciones constitucionales a derechos, desarticulan en buena medida el sistema establecido por el poder revisor de la Constitución, contradiciendo además de una norma constitucional, una decisión política fundamental que apoya tal norma.

Por otro lado, se obliga a los jueces a tomar decisiones potencialmente inconvencionales e inconstitucionales que incluso comprometerán la responsabilidad internacional del Estado. En tal sentido, es necesaria la revisión de estos criterios para instalar de nueva cuenta el principio propersona como regla operativa completa al interior del parámetro de regularidad constitucional y así restablecer el adecuado diseño de la ley suprema de la Unión.

\section{BIBLIOHEMEROGRAFÍA}

AlEXY, Robert, Teoría de los derechos fundamentales, trad. de Ernesto Garzón Valdés, Madrid, Centro de Estudios Constitucionales, 2002. 
Astudillo, César, "El bloque y el parámetro de constitucionalidad en la interpretación de la Suprema Corte de Justicia de la Nación", en CARBONELL, Miguel et al. (coords.), Estado constitucional, derechos humanos, justicia y vida universitaria. Estudios en homenaje a Jorge Carpizo, Estado constitucional, t. IV, vol. I, México, UNAM, Instituto de Investigaciones Jurídicas, 2015.

Beltrán de Felipe, Miguel y GonzÁlez García, Julio V., Las sentencias básicas del Tribunal Supremo de los Estados Unidos de América, Madrid, Boletín oficial del Estado, Centro de Estudios Políticos y Constitucionales, 2006.

BIDART CAMPOS, Germán, Tratado elemental de derecho constitucional argentino, t. III, El derecho internacional de los derechos humanos y la reforma constitucional de 1994, Buenos Aires, Ediar, 1995.

CABallero OchOA, José Luis, "Cláusula de interpretación conforme y el principio propersona”, en CARBonell, Miguel y SALAZAR, Pedro, La reforma constitucional de derechos humanos. Un nuevo paradigma, México, UNAM, Instituto de Investigaciones Jurídicas-Suprema Corte de Justicia de la Nación, 2012.

CARBonell, Miguel y SAlAZAR, Pedro, La reforma constitucional de derechos humanos. Un nuevo paradigma, México, UNAM, Instituto de Investigaciones Jurídicas-Suprema Corte de Justicia de la Nación, 2012.

CARMOnA TinOCO, Jorge Ulises, "La reforma y las normas de derechos humanos", en CARBOnell, Miguel y SAlAZAR, Pedro, La reforma constitucional de derechos humanos. Un nuevo paradigma, México, UNAM, Instituto de Investigaciones Jurídicas-Suprema Corte de Justicia de la Nación, 2012.

CARPIZO, Jorge, Estudios constitucionales, México, UNAM, Instituto de Investigaciones Jurídicas, 1996.

Cossío, José Ramón et al., La construcción de las restricciones constitucionales a los derechos humanos, México, Porrúa, 2015.

Cueva, Mario de la, Teoría de la Constitución, México, Porrúa, 2008.

FAVOREU, Louis y RUBIO LlORENTE, Francisco, El bloque de la constitucionalidad, Madrid, Universidad de Sevilla, Cuadernos Civitas,1991.

FERrajoli, Luigi, Democracia y garantismo, Madrid, Trotta, 2008.

FERRER MAC-GREGOR, Eduardo, "Interpretación conforme y control difuso de convencionalidad”, en CARBOnEll, Miguel y SAlazar, Pedro, 
La reforma constitucional de derechos humanos. Un nuevo paradigma, México, UNAM, Instituto de Investigaciones Jurídicas-Suprema Corte de Justicia de la Nación, 2012.

FIORAVANTI, Maurizio, Los derechos fundamentales. Apuntes de historia de las Constituciones, Madrid, 1996.

Fraga, Gabino, Derecho administrativo, 37a. ed., México, Porrúa, 2015.

FiX-ZAMUdio, Héctor y VALENCIA CARMONA, Salvador, Derecho constitucional mexicano y comparado, 9a. ed., México, UNAM-Porrúa, 2017.

GARCÍA DE ENTERRÍA, Eduardo, La Constitución como norma y el Tribunal Constitucional, 3a. ed., Madrid, Civitas, 1983.

GARCíA JARAMILLO, Leonardo, "Desafíos de la interamericanización del derecho: la contribución del ius constitutionale commune", en BOGDANDY, Armin von et al. (coords.), Ius constitutionale commune en América Latina, México, Instituto de Estudios Constitucionales de Querétaro y Max Planck Institute, 2017.

GARCÍA MÁYNEZ, Eduardo, Introducción al estudio del derecho, 65a. ed., México, Porrúa, 2015.

GARCÍA RAmíreZ, Sergio y Morales SÁNCHEZ, Julieta, La reforma constitucional sobre derechos humanos (2009-2022), México, UNAM-Porrúa, 2012.

Hamilton, A. et al., El Federalista, trad. Gustavo Velasco, México, Fondo de Cultura Económica, 2000.

MATA QUINTERO, Gerardo, "El principio propersona: la fórmula del mejor derecho", Cuestiones Constitucionales, Revista Mexicana de Derecho Constitucional, núm. 39, julio-diciembre de 2018.

OтTо, Ignacio de, Derecho constitucional, sistema de fuentes, Barcelona, Ariel Derecho, 1998.

Nogueira Alcalá, Humberto, "El bloque constitucional de derechos en Chile. El parámetro de control y consideraciones comparativas con Colombia y México: Doctrina y Jurisprudencia”, Estudios Constitucionales, Chile, año 13, núm. 2, 2015.

ORTEGA GARCÍA, Ramón, "El enfoque restrictivo de los derechos humanos: Comentarios a la contradicción de tesis 293/2011", Cuestiones Constitucionales, Revista Mexicana de Derecho Constitucional, núm. 32, enero-junio de 2015. 
PINTO, Mónica, "El principio pro homine. Criterios de hermenéutica y pautas para la regulación de los derechos humanos", en ABREGÚ, Martis y CourTis, Christian (comps.), La aplicación de los tratados sobre derechos humanos por los tribunales locales, Buenos Aires, Editores del Puerto, 1997.

Pou, Francisca, "Lo que quisiera que la Corte hiciera por mí: lealtad constitucional y justicia dialógica en la aplicación de la CT 293/2011", en Caballero Ochoa, José Luis y SÁnchez Gil, Rubén (coords.), Derechos constitucionales e internacionales, México, Tirant lo Blanch, 2018.

SILVA, Fernando, "Derechos humanos y restricciones constitucionales: ¿reforma constitucional del futuro $v s$. interpretación constitucional del pasado? (comentario a la C. T. 293/2011 del Pleno de la SCJN", Cuestiones Constitucionales. Revista Mexicana de Derecho Constitucional, núm. 30, enero- junio de 2017.

UPRIMY, Rodrigo, El bloque de constitucionalidad en Colombia, Colombia, Universidad Nacional-ENS, 2005, disponible en: www.http://redescuelascsa.com/sitio/repo/DJSBloque_Constitucionalidad(Uprimny).pdf.

Fecha de recepción: 12 de noviembre de 2017.

Fecha de aceptación: 12 de marzo de 2019.

Esta obra está bajo una Licencia Creative Commons Atribución-NoComercial-SinDerivar 4.0 Internacional, IIJ-UNAM. 